\title{
Effects of simultaneous utilization of natural zeolite and magnetic water on engineering properties of self-compacting concrete
}

\author{
Mohammad Hajforoush $^{a}, \operatorname{Rahmat~Madandoust~}^{b}$, Mostafa Kazemi $^{b}$ \\ ${ }^{a}$ Department of Civil Engineering, Semnan University, Semnan, Iran \\ ${ }^{\mathrm{b}}$ Department of Civil Engineering, University of Guilan, P.O. Box 3756, Rasht, Iran
}

Corresponding Author: Rahmat Madandoust

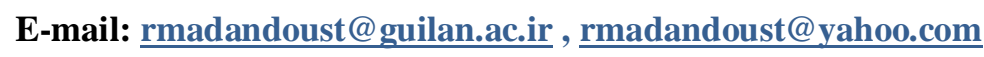

Tel: +989113314970

Fax: +981333690271

\begin{abstract}
A study was performed to assess the effects of magnetic water with different percentages of natural zeolite (NZ) on selfcompacting concrete (SCC) mixes. Over the past decades, a limited number of studies were conducted by researches on the effects of magnetic water on SCC mixes. In addition, it seems that pozzolanic materials such as NZ can affect performance of magnetic water in SCC mixes. Following this, the present study was aimed to survey engineering properties of selfcompacting concrete (SCC) containing magnetic water and NZ. To achieve this goal, slump flow, $\mathrm{T}_{50}, \mathrm{~V}$-funnel, L-box and visual stability index (VSI) were employed to evaluate the rheological properties of concrete mixes. Furthermore, hardened properties were investigated by means of compressive strength, splitting tensile strength, modulus of elasticity and water absorption tests. The concrete test results demonstrated that $20 \%$ NZ inclusion and magnetic water in SCC with the waterbinder (W/B) ratio of 0.37 led to an optimum mix design and also this mixture could contribute to an increase in compressive strength, splitting tensile strength and modulus of elasticity up to $25 \%, 8 \%$ and $9 \%$, respectively.
\end{abstract}

Keywords: Self-compacting concrete, Magnetic water, Zeolite, Engineering properties. 


\section{Introduction}

Self-compacting concrete (SCC) can be considered as a revolutionary concrete mix which able to flow easily in congested rebar arrangements by means of its self-weight without needing vibrator (Siddique, 2011; Jalal et al. 2012). Also, the use of SCC can lead to lower time required for pouring concrete and building more reliable and durable structures where these positive impacts dominate the undesirable effect of SCC including higher expense owing to need for higher chemical admixtures (Beygi et al., 2013; Topcu and Bilir, 2009). Furthermore, recently a study by Pelisser et al. (2018) showed that an efficient selfcompacting concrete containing a low cement content which reduces the hazardous burden on the environment can be produced. This innovative concrete mix first proposed by Okomora in 1986 and the prototype of SCC was subsequently offered in 1988 at the University of Tokyo (Okamura and Ouchi, 2003). Later on, SCC has been drawn the attention of researchers all over the world to attain higher durable concrete.

Engineering properties of concrete can be affected by types of water used in concrete mixes. Of all types of water, magnetic water, produced after passing through a magnetic field of certain strength, can disperse cement particles from each other which can lead to avoiding agglomeration of cement particles and generating hydration layers surrounding them (Singh and Naval, 2016). This procedure causes to improve flowability of concrete due to passing water easily around the separated cement particles. On the other hand, the large quantity of 
cement in the concrete leads to imposing a detrimental impact on the environment owing to emitting 0.54 tons of $\mathrm{CO}_{2}$ from one ton of cement production (Gesoglu et al., 2012). But, molecules of magnetic water can easily penetrate into the cement particles, and improve microporous structure of the hardened concrete, while the molecules of tap water tend to agglomerate and form clusters; hence, magnetic water enhances mechanical properties of concrete better, and subsequently it can lead to using 5\% less cement in concrete mixture compared to control mixture prepared by tap water to achieve the target strength of concrete. In addition, when magnetic water improves the micro-pore distribution of concrete, it can prevent somehow from forming large ice crystals in concrete mixture and subsequently improve resistance to freezing (Chau, 1996; Fu and Wang, 1994; Otero et al., 2016). Meanwhile, magnetic water does not require addition of chemical admixtures to enhance compressive strength of concrete; therefore, it prevents from environmental pollution (Jain et al., 2017). In addition, as reported by Su and $\mathrm{Wu}$ (2003), the reaction of cement particles with tap water leads to agglomeration of molecules of tap water and subsequently generating larger calcium hydroxide plates, while the utilization of magnetic water in concrete mixture can contribute to generating smaller calcium hydroxide crystals which lead magnetic water molecules to reacting efficiently with cement particles. They concluded this matter is the reason of why the compressive strength of concrete mixed with magnetic water is higher than that of concrete mixed with tap water. Concerning this, as shown by Afshin et al. (2010), the 
effects of magnetic water on high strength concrete caused an increase in compressive strength and slump up to $18 \%$ and $45 \%$, respectively.

The durability characteristics of concrete can be improved with the inclusion of pozzolanic materials which are less harmful to the environment (Oner and Akyuz, 2007; Yang et al., 2007; Jahandari et al., 2018; Saberian et al., 2017). As one of pozzolanic materials, natural zeolite (NZ) is hydrated alumino-silicates where it includes large quantities of chemical components of $\mathrm{SiO}_{2}$ and $\mathrm{Al}_{2} \mathrm{O}_{3}$, similar to other pozzolanic additions such as fly ash (Dehwah, 2012), silica fume (Madandoust et al., 2011), metakaolin (Madandoust and Mousavi, 2012) and ground granulated blast furnace slag (Babu et al., 2008). As surveyed by Ahmadi and Shekarchi (2010), with the inclusion of 5\%, 10\%, 15\% and $20 \% \mathrm{NZ}$, compressive strength of concrete with the water-binder (W/B) ratio of 0.40 increased up to $14 \%, 16 \%, 23 \%$ and $25 \%$, respectively, compared to the control mixture. Canpolat et al. (2004) found that 5\% NZ in normal concrete led to an increase in compressive strength at early ages while setting time was reduced by replacing cement particles with NZ. In addition, Mola-Abasi et al. (2018) demonstrated that the inclusion of NZ leads to increasing the shear strength of concrete and peak axial stress. Poon et al. (1999) showed that pozzolanic reaction in the presence of NZ is lower and higher than that in the presence of silica fume and fly ash, respectively. In addition, as reported by Najimi et al. (2012), the inclusion of NZ led to the desirable impacts on water penetration, chloride ion penetration, corrosion rate and drying shrinkage of concrete. Valipour et al. (2014) found that NZ at 10\%, $20 \%$ and $30 \%$ 
replacement levels increased compressive strength of normal concrete up to $64.3 \%, 69.7 \%$ and $60.3 \%$, respectively, and also this content caused to produce a highly environmentally friendly concrete. They also concluded that concrete containing $20 \% \mathrm{NZ}$ can be considered as an optimum mix design where this admixture most efficiently affected the global warming index. Some researchers have reported the fact that NZ can prevent from poor expansion owing to alkali silica activity (Feng and Hao, 1998). In addition, a study by Chan and Ji (1999) on high performance concrete containing zeolite, silica fume and pulverized fuel ash revealed that zeolite had higher and lower performance than pulverized fuel and silica fume, respectively, to enhance the compressive strength and decrease the initial surface absorption and the chloride diffusion. As observed by Uysal and Tanyildizi (2012), self-compatibility properties happened only when the amount of NZ was 5\% replacement of cement particles. Although, SCC mixes were made with two types of NZ by Cioffi et al. (2006), at a replacement level of $40 \%$, which were classified as slump flow class 1 (SF1) (EFNARC, 2005). In addition, as reported by Ranjbar et al. (2013), NZ in SCC mixes is capable of improving the rate of flowability, mechanical properties and durability of cement and concrete composites. As displayed in some studies, engineering properties of concrete mixes can be improved with the inclusion of both magnetic water and pozzolanic materials. As shown by Su et al. (2000; 2003), the compressive strength of concrete with the inclusion of magnetic water and fly ash or granulated blast-furnace slag increased up to $10-20 \%$ compared to concrete control mix made with tap water where the highest compressive strength of 
concrete was obtained when the magnetic strength was ranging from 0.8 to 1.2 Tesla. Another study conducted by Bharath et al. (2016) demonstrated that the workability (slump flow) of concrete containing copper slag powder increased up to $50 \%$ because of using magnetic water instead of tap water in concrete mix. Meanwhile, Ghods (2014) indicated that the increase in compressive and tensile strength of SCC mixes containing magnetic water and nanosilica at early ages was more than that at older ages. Furthermore, Gholhaki et al. (2018) recently investigated the effects of simultaneous utilization of magnetic water and various pozzolanic materials such as silica fume, metakaolin, rice husk ash and fly ash on SCC mixes. They revealed that the compressive strength of SCC mixed with magnetic water and $20 \%$ silica fume increased up to $49 \%$ compared to that of SCC control mix made with tap water. They also concluded that magnetic water in SCC caused to decline need for high range water reducer (HRWR) up to 45\%. In addition, the dosage of HRWR increased for SCC containing all pozzolanic materials except fly ash compared to SCC control mix made with magnetic water. According to these studies, it can be inferred that the performance of magnetic water in SCC mixes is affected by the inclusion of various pozzolanic materials. So, the present study is an effort to assess the effects of simultaneous utilization of magnetic water and different percentages of natural zeolite (NZ) (0-20\% by mass of cement) on SCC mixes where the W/B ratios were 0.37 and 0.45 and the magnetic strength of water was considered equal to 0.8 Tesla. To achieve this goal, slump flow, required time of SCC to reach $500 \mathrm{~mm}$ length slump-flow diameter $\left(\mathrm{T}_{50}\right), \mathrm{V}$-funnel, L-box and visual stability index (VSI) were employed 
to evaluate the rheological properties of concrete mixes. On the other hand, hardened properties were evaluated by means of water absorption test at the age of 28 and 90 days and using compressive strength, splitting tensile strength, modulus of elasticity at the ages of 7 , $14,28,42$ and 90 days.

\section{Experimental plan}

\subsection{Materials}

Table 1 shows the chemical compositions of NZ and cement. In addition, NZ particle size analysis was carried out using the laser diffraction method (Fig. 1). The results showed that the $\mathrm{NZ}$ was in the range of $0.8-200 \mu \mathrm{m}$, and the surface area of $\mathrm{NZ}$ was equal to $3220 \mathrm{~cm}^{2} / \mathrm{gr}$. Meanwhile, in present study, Type II Portland cement and NZ were utilized with densities of

3.15 and $2.15 \mathrm{~g} / \mathrm{cm}^{3}$, respectively. The resource of fine aggregate with a specific density of $2.6 \mathrm{~g} / \mathrm{cm}^{3}$ was natural river sand where the value of water absorption of fine aggregate was equal to $2.38 \%$. In addition, the nominal maximum size and water absorption value of crushed gravel as coarse aggregate with a specific density of $2.65 \mathrm{~g} / \mathrm{cm}^{3}$ were equal to $19 \mathrm{~mm}$ and $1.01 \%$, respectively.

Meanwhile, the magnetic strength of water was considered equal to 0.8 Tesla as compared to the SCC produced with tap water. According to EFNARC (2005), HRWR based on carboxylate was used with density of $1.15 \mathrm{~g} / \mathrm{cm}^{3}$ on the basis of ASTM C494 (2004).

\subsection{Mixture proportion and test procedure}


In this study, twelve SCC mixes were considered in two groups namely G1 and G2 based on the $\mathrm{W} / \mathrm{B}$ ratios of 0.37 and 0.45 , respectively. The total weight of cementitious materials was $400 \mathrm{~kg} / \mathrm{m}^{3}$. To prepare SCC mixes, two of the mixes used tap water and no NZ (control mix) and two of the mixes contained magnetic water but no NZ. As shown in Table 2, ten of the mixes were made with magnetic water and incorporating 5\%,10\%, $15 \%$ and $20 \%$ replacement levels of NZ. It is noteworthy that since the water absorption is higher in NZ than in cement, the higher absorption of concrete incorporating NZ is inevitable; therefore, with increasing the amount of NZ in SCC mixes, we needed higher HRWR dosage to satisfy passing ability criteria as reported by Markiv et al. (2016). That's why the dosage of HRWR varied for different concrete mixes.

For producing magnetic water, first, the electrical current flowed through coils of wire, wrapped around the water pipe. When electricity flowed through a wound up coil of wire, it generated a magnetic field that filled the area around the coil in a particular pattern, shown in Fig. 2. Then, water was exposed to the magnetic field as it flowed through the pipe between the magnets. After passing through a magnetic flux, the structure of water was aligned in one direction after magnetization, and the molecule sizes changed after the bond angle changed; therefore, viscosity and surface area increased by magnetization, hence the hydration rate increased (Afshin et al. 2010; Ubale et al. 2016).

In present study, the procedure of SCC mixes, proposed by Khayat et al. (2000), was employed. In first step, natural coarse and fine aggregates were homogenized for $30 \mathrm{~s}$ at 
normal mixing speed. Later on, half of the magnetic water was added into the mixer while mixing goes on for $1 \mathrm{~min}$. Thereafter, the mixture was rested for $1 \mathrm{~min}$ so that the aggregates could absorb. Then, cement and fillers were added and mixed for one more minute. Finally, the remaining water and HRWR were introduced to the mixture, while mixing was going on for 3 min. 15 x $30 \mathrm{~cm}$ cylindrical samples were made and tested to determine $7,14,28,42$ and 90 days splitting tensile strength and modulus of elasticity according to ASTM C496 (2004) and ASTM C469 (2002), respectively. By means of compression testing machine, 15 $\mathrm{cm}$ cubes were tested at the ages of 7, 14, 28, 42 and 90 days. Based on ASTM C642 (2006), absorption test was also conducted on cubic specimens at the ages of 28 and 90 days. Another matter is that the results, obtained in all tests, were the average of 3 numbers of specimens. In addition, all specimens have been taken out after $24 \mathrm{~h}$ and kept under tap water curing regime until the testing day.

\section{Results and discussions}

\subsection{Fresh concrete results}

In this study, slump flow, $\mathrm{T}_{50}, \mathrm{~V}$-funnel, L-box and visual stability index (VSI) were employed to assess fresh properties of SCC containing magnetic water and NZ where there existed a good compatibility between rheological properties of fresh mixes and the EFNARC (2005) recommendations.

\subsubsection{Slump flow}


The results of slump flow test for SCC containing NZ and magnetic water are presented in Fig. 3. It can be shown that the slump flow of mixes varied from 670 to $710 \mathrm{~mm}$ when the dosage of HRWR maintained in the range of between 2.85 and $9.88 \mathrm{~kg} / \mathrm{m}^{3}$. The use of magnetic water in SCC control mix (Ctrl (MW)) led to an increase in slump flow up to 3\% and $2 \%$ and a decrease in HRWR up to $45 \%$ and $75 \%$ compared to SCC control mix made with tap water $(\mathrm{Ctrl}(\mathrm{NW}))$ when the $\mathrm{W} / \mathrm{B}$ ratios were equal to 0.37 and 0.45 , respectively. Magnetic water can disperse cement particles from each other and generate hydration layers surrounding them (Singh and Naval, 2016) which can lead to requiring lower HRWR. As shown in Fig. 3, the use of NZ caused more need for HRWR to maintain slump flow in a desired range substantially where the highest dosage of HRWR was used for SCC containing $20 \% \mathrm{NZ}$ with the W/B ratio of $0.37\left(9.88 \mathrm{~kg} / \mathrm{m}^{3}\right)$ which was $213 \%$ more than that for SCC control mix made with magnetic water. Similar results were also observed by Najimi et al. (2012) and Feng et al. (1990) which could be owing to the higher surface area of NZ particles compared to Portland cement. This conclusion was also achieved by Ahmadi and Shekarchi (2010). With the inclusion of 5 and $10 \%$ NZ in SCC mixed with magnetic water, the slump flow decreased for both G1 and G2 concrete groups. The reason is that NZ particles, having small pores and channel, can absorb mixing water as explained by Ranjbar et al. (2013). But with increasing the amount of NZ in SCC mixes, the slump flow increased. This matter can be due to needing higher HRWR dosage for SCC incorporating 15 and $20 \%$ NZ compare to 5 and $10 \%$ NZ. 
According to EFNARC (2005), all concrete mixes can be classified as slump flow class 2 (SF2) which is ranged between 660 and $750 \mathrm{~mm}$. This class is suitable for many normal applications such as walls and columns. It is noteworthy that SCC contained higher content of $\mathrm{NZ}$ with the W/B ratios of 0.37 and 0.45 needs higher HRWR dosage to remain in SF2 class.

\subsection{2. $T_{50}$ flow time and $V$-funnel time}

According to Fig. 4 , the values of $\mathrm{T}_{50}$ flow time varied from 2.85 to $5.14 \mathrm{~s}$ where SCC containing various percentages of $\mathrm{NZ}$ had higher $\mathrm{T}_{50}$. The reason is that the inclusion of $\mathrm{NZ}$ led to a decrease in flowability and an increase in plastic viscosity. As indicated in Fig. 5, there existed similar trends between the results of $\mathrm{T}_{50}$ flow time and $\mathrm{V}$-funnel for all mixes. Figs. 4 and 5 indicate that the inclusion NZ in SCC made with magnetic water led to an increase in viscosity by increasing flow time, while the reverse was true in the absence of NZ in SCC. By considering the regression equations, presented in Fig. 6, a good correlation was obtained between $\mathrm{T}_{50}$ and $\mathrm{V}$-funnel tests which were labeled with letters of $\mathrm{T}$ and $\mathrm{VF}$, respectively. Following this, it can be inferred that either $\mathrm{T}_{50}$ slump flow or $\mathrm{V}$-funnel flow test are sufficiently qualified to evaluate the relative viscosity and cohesiveness of SCC. As shown in Figs. 4 and 5, the ranges of $\mathrm{T}_{50}$ flow time and V-funnel time were limited between 2-5 s and 9-25 s, respectively, which demonstrated that restricted values according to EFNARC (2005) were very satisfied with most of flow times, obtained in present study. 


\subsubsection{L-box test}

The L-box is one test method developed to assess the passing ability and blocking resistance of SCC. A moveable gate divides the vertical and the horizontal section. The vertical section is filled with concrete and the gate is lifted to allow concrete to follow past the reinforcement bars and into the horizontal section. To assess the passing ability, the ratio between the concrete height at the end of the horizontal section $\left(\mathrm{H}_{2}\right)$, and the height of the remaining concrete in the vertical section $\left(\mathrm{H}_{1}\right)$ has been proposed. This is usually referred to as the blocking ratio $\left(\mathrm{H}_{2} / \mathrm{H}_{1}\right)$ that a value closer to 1 is better for meeting the flow-ability and passing ability criteria (Billberg, 1999). As indicated in Fig. 7, values for L-box blocking ratio for SCC containing various percentages of NZ varied from 0.8 to 0.92 where the L-box blocking ratio of 0.8 satisfied the minimum requirement of EFNARC(2005). It is noteworthy that there existed better passing ability for SCC control mix containing magnetic water than other SCC mixes. It can be due to the fact that magnetic water can disperse cement particles from each other and generate hydration layers surrounding them (Singh and Naval, 2016). Yet, by replacing cement particles with NZ, the lower blocking ratio was attained for SCC mixes. This may be due to absorbing magnetic water by NZ particles, having small pores and channel, and also undesirable effect of self-weight of NZ particles, dominating the effect of HRWR dosages required for SCC mixes.

\subsubsection{Visual stability index (VSI)}


During the slump flow test, in no case SCC mixes show any visible sign of segregation or bleeding. Broken split tensile test specimens were also used for assessing any segregation phenomenon in aggregates. The uniformity in the distribution of coarse aggregate in the broken split specimens indicated proper segregation resistance of mixtures. For all SCC mixes, after mixing, VSI values were obtained in the range of 0-1 based on EFNARC (2005) which indicate proper stability of concrete mixes.

\subsection{Hardened concrete results}

\subsubsection{Compressive strength}

As shown in Fig 8, the effects of simultaneous utilization of magnetic water and 5\%, 10\%, $15 \%$ and $20 \% \mathrm{NZ}$ on compressive strength of SCC mixes with the W/B ratios of 0.37 and 0.45 were evaluated at the ages of $7,14,28,42$ and 90 days where compressive strength for

G1 and G2 concrete groups was in the range of 22.8-58.9 $\mathrm{MPa}$ and 25.4-50.8 $\mathrm{MPa}$, respectively. The dispersion of NZ has significant effects on the properties of cementitious composites. Concerning this, it can be stated that HRWR can form repulsive electrostatic forces on $\mathrm{NZ}$ and cement particles and prevent from the formation of agglomeration in concrete mixture and disperse these particles in aqueous phase as reported by Safiuddin (2008). Meanwhile, the magnetic field disperses water clusters more and also breaks them into smaller clusters; therefore, water molecules penetrate into cement particles easily and subsequently prevent somehow from cement agglomerations in concrete mixes (Esfahani et 
al., 2018). Generally, in this study, it can be inferred that the dispersion of NZ in concrete mixes can be considered uniform, which can lead to completing the hydration process better and improving the strength of concrete mixes more. For instance, of all SCC mixes, $20 \%$ usage of NZ in SCC prepared with magnetic water accounted for the highest strength development after 28 days with the W/B ratios of 0.37 and 0.45 . This matter also showed that simultaneous utilization of $\mathrm{NZ}$ and magnetic water in SCC can efficiently decrease harm to the environment by decreasing the amount of cement in SCC up to $20 \%$. Valipour et al. (2014) also concluded that normal concrete containing 20\% NZ had the highest compressive strength compared to other percentages of NZ. Similar conclusions were also revealed by Su et al. $(2000 ; 2003)$ where they investigated the effects of simultaneous utilization of magnetic water and granulated blast furnace slag and fly ash on concrete. They revealed that water molecules can be broken up by magnetic force where the usage of magnetic water in concrete mixture can contribute to generating smaller calcium hydroxide crystals. Later on, water molecules can easily pass through the hydration layer and into the cement particles. This procedure leads magnetic water molecules to reacting efficiently with cement particles and causes to complete hydration process more. Another matter is that hydration layer, made by magnetic water, reacts quickly to cement particles at early ages. Yet, after completing the hydration layer around the cement particles, water molecules cannot efficiently react to cement particles for continuing the hydration process. This matter seems to be the leading cause of why the compressive strength of SCC incorporating NZ increased slower at older 
ages which was reported by Ghods (2014). As expected, the results demonstrated that, in every age, the compressive strength of SCC mixes with W/B ratio of 0.45 was lower than that with W/B ratio of 0.37 . Similar results were also observed by Nikbin et al. (2014) for SCC mixes with W/B ratios of 0.45 and 0.65 . This can be explained by the fact that with decreasing W/B ratio, the number of microcracks between aggregate particles and paste, and porosities of the hardened paste generally reduces. Therefore, a higher strength can be obtained (Chau, 1996). This matter was also revealed by Poon et al. (1999) for normal concrete or cement paste with NZ. Furthermore, compressive strength of SCC mixes containing NZ was obtained lower than that of SCC control mix made with magnetic water at early ages, while the reverse was true about them at older ages. As explained by Ranjbar et al. (2013), the reason is that mixing water can be absorbed by NZ which has extremely small pores and channel. That's why, at the early age, the activity of magnetic water in SCC containing NZ cannot be efficiently improved compared to SCC control mixed with magnetic water. Following this, Valipour et al. (2013) also observed that completing the hydration process is associated with requiring long-term curing for NZ. For instance as shown in Fig. 8a, there was a decrease of about $8 \%$ in 7 days compressive strength of NZ20-L in comparison to $\mathrm{Ctrl}(\mathrm{NM})-\mathrm{L}$ while this value increased to $24 \%$ at the age of 90 days.

As shown in Fig. 8, the mid-values of standard deviation (SD) for SCC control mixture made with tap water with W/B ratio of 0.37 and 0.45 were 2.2 and $2.4 \mathrm{MPa}$, respectively, while these mid-values for other mixes were less than $1 \mathrm{MPa}$. This may be due to the fact 
that, first, NZ is finer than cement particles. Second, magnetic water molecules can react efficiently with cement particles compared to tap water. These two features can help concrete mixes to complete the hydration process better; therefore, the SD values for SCC mixes made with magnetic water and NZ are less scattered compared to those of SCC control mixture made with tap water.

\subsubsection{Splitting tensile strength}

The results obtained by means of tensile splitting test, for SCC mixes made with magnetic water and incorporating 5\%,10\%, $15 \%$ and $20 \%$ replacement levels of NZ with the W/B ratios of 0.37 and 0.45 are shown in Fig. 9. The general trend for tensile strength was almost similar to what observed for the compressive strength, similar to results, obtained by Ramezanianpour et al. (2015), for normal concrete containing NZ. The values of tensile strength for G1 and G2 concrete groups were in the range of 2.4-4.1 $\mathrm{MPa}$ and 2.5-3.9 $\mathrm{MPa}$, respectively. Similar to compressive strength test results, tensile strength of SCC mixes containing NZ was obtained lower than that of SCC control mix made with magnetic water at early ages, while the reverse was true about them at older ages. This manner can be due to the fact that NZ enhances the transition zone structure, a region with a higher porosity, by consuming Portlandite crystals and forming secondary calcium silicate hydrate as reported by Ramezanianpour et al. (2015) for normal concrete incorporating NZ. In addition, the lower W/B ratio of 0.37 could lead to better tensile strength. Meanwhile, although the tensile strength of SCC mixes enhanced with increasing ages as compressive strength test, the 
increase of tensile strength was lower than corresponding compressive strength. The same behavior was also reported by Guneyisi et al. (2008) for normal concrete containing metakaolin. Furthermore, From Fig. 9, it can be inferred that SCC incorporating 20\% NZ attained the highest tensile strength developments among different NZ inclusion after the age of 28 days. Since concrete has been known for its abilities in compressive strength, and it is apparent that the tensile strength of concrete is more sensitive than the compressive strength (Madandoust et al., 2017), the SD values of tensile splitting test were more dissipated compared to those of compressive strength test as shown in Fig. 9.

The relationship between the compressive strength and splitting tensile strength is presented in Fig. 10 where two equations of $\mathrm{f}_{\mathrm{t}}=1.01\left(\mathrm{f}_{\mathrm{cy}}\right)^{0.35}$ and $\mathrm{f}_{\mathrm{t}}=0.5\left(\mathrm{f}_{\mathrm{cy}}\right)^{0.54}$ with high correlation coefficients of $\mathrm{R}^{2}=0.91$ and $\mathrm{R}^{2}=0.94$ for $\mathrm{G} 1$ and $\mathrm{G} 2$ concrete groups, respectively, were achieved. The values obtained by these two equations are very close to those, recommended by CEB-FIP (1989) and ACI 318-05 (2005). Furthermore, the appropriate conversion factor, proposed by Domone (2007), was employed for converting the cube compressive strength to cylindrical strength.

\subsubsection{Modulus of elasticity}

Fig. 11 shows the influence of NZ contents on modulus of elasticity with the W/B ratios of 0.37 and 0.45 . It can be seen that the modulus of elasticity of SCC mixes increased with W/B ratio decreasing. The maximum enhancement of modulus of elasticity was about $43.2 \mathrm{GPa}$ 
for G1 concrete group and 39.54 GPa for G2 concrete group where $20 \%$ usage of NZ in SCC prepared with magnetic water for G1 and G2 concrete groups was attained the highest modulus of elasticity development. For this content, there is a clearly higher modulus of elasticity of SCC mixed with magnetic water and containing NZ than that of SCC control mix made with magnetic and tap water after 28 days. Similar to compressive strength test, the SD values of modulus of elasticity for SCC control mixture made with tap water were more dissipated compared to those of SCC mixes made with magnetic water and NZ as shown in Fig. 11.

The modulus of elasticity of the SCC mixes vs. corresponding 28 days compressive strength is presented in Fig. 12. Based on the results at 28 days, the equations of $E_{C}=1.64\left(f_{c y}\right)^{0.84}$ and $E_{C}=3.04\left(f_{c y}\right)^{0.64}$ have been presented as the relationship between the compressive strength and modulus of elasticity where $R^{2}=0.95$ and $R^{2}=0.96$ have been considered as correlation coefficients for SCC mixes with the W/B ratios of 0.37 and 0.45 , respectively. Regarding this, the results were compared with values predicted by CEB-FIP (1989) and ACI 318-05 (2005). As shown in Fig. 12, the mean relationship proposed by ACI model provided little lower modulus of elasticity value than that of SCC mixes with the ratio of 0.37. In addition, CEB-FIP offered nearly the same modulus of elasticity value as SCC mixes made with the $\mathrm{W} / \mathrm{B}$ ratios of 0.45 .

\subsubsection{Water absorption}


Fig. 13 shows water absorption values for all SCC mixes at the ages of 28 and 90 days. Based on the CEB-FIP (1989) recommendation, water absorption values of concrete with poor, average and good qualifications are in the ranges of 5\% and above, 3-5\% and 0-3\%, respectively. With respect to this classification, the qualifications of all SCC mixes are categorized as "good"' and "average'. At the age of 28 days, the water absorption for G1 and G2 concrete groups were in the range of $2.18-4.2 \%$ and $2.9-4.6 \%$, respectively. These values were in the range of $1.8-3.6 \%$ and $2.2-4.1 \%$, respectively, for SCC mixes at the age of 90 days. It is noteworthy that NZ particles are finer than cement particles. This can provide the higher surface area of NZ particles in contact with molecules of water for completing the hydration process compared to Portland cement. That's why the dissipation of SD values for water absorption decreased with increasing the amount of NZ as shown in Fig. 13.

As displayed in Fig. 13, for both concrete groups at the ages of 28 and 90 days, it was found that the highest and lowest points were attained by SCC control mix made with tap water and SCC mixed with magnetic water and incorporating $20 \%$ NZ, respectively. This result shows the effect of $\mathrm{NZ}$ in the reduction in water absorption compared to SCC control mix made with magnetic water and tap water which was confirmed by Ahmadi and Shekarchi (2010) who demonstrated that normal vibrated NZ concrete mixtures showed lower water absorption than the control mixture. Meanwhile, NZ in SCC mixes could decrease the water absorption of SCC with increasing curing ages. This can be owing to the pozzolanic activity 
of NZ during the prolonged curing. Furthermore, the water absorption of SCC mixtures has a decreasing tendency with the decreasing W/B ratio.

\section{Conclusions}

In this study, the simultaneous utilization of magnetic water and $5 \%, 10 \%, 15 \%$ and $20 \%$ NZ in SCC mixes with the W/B ratios of 0.37 and 0.45 was evaluated. Based on this experimental evaluation, the following conclusions can be exploited:

- The dosage of HRWR can be reduced up to $45 \%$ using magnetic water in SCC mixture.

Furthermore, NZ in SCC made with magnetic water will enhance the dosage of HRWR, needed for flowability of mixes, compared to SCC mixture contained magnetic water but no NZ.

- Slump flow properties according to EFNARC recommendations were satisfied with SCC containing various percentages of NZ. Meanwhile, the consumption of NZ in SCC mixes can improve viscosity and flowability, as criteria for self-compactability.

- SCC, made with various percentages of NZ, can achieve higher viscosity in V-funnel and $\mathrm{T}_{50}$ tests. Regarding this, the consumption of $20 \% \mathrm{NZ}$ and magnetic water in SCC with the W/B ratio of 0.37 caused to obtain the highest viscosity where the $\mathrm{T}_{50}$ and $\mathrm{V}$ funnel times of this mix increased up to $9 \%$ and $19 \%$, respectively, higher than SCC mixture contained tap water and no NZ. 
- By utilizing magnetic water in SCC mixes, passing ability in L-box test increased up to $7 \%$. Moreover, this value can be attained more than $8 \%$ for SCC incorporating $5 \%$ $\mathrm{NZ}$ with the W/B ratio of 0.37 .

- Similar to tensile strength test results, compressive strength of SCC containing NZ was obtained lower than that of SCC control mix made with magnetic water at early ages, while the reverse was true about them at older ages where $20 \%$ usage of NZ in SCC prepared with magnetic water accounted for the highest compressive strength at the age of 90 days with the W/B ratios of 0.37 and 0.45 . It is noteworthy that the compressive strength of SCC incorporating NZ increased slower at older ages.

- The modulus of elasticity of SCC mixes with the W/B ratio of 0.45 is estimated by ACI 318-05 relationship a little lower. Meanwhile, CEB-FIP relationship predicts nearly the same values of modulus of elasticity obtained for SCC mixes with the W/B ratio of 0.37 .

- Magnetic water in SCC resulted in a decrease in water absorption values up to $10 \%$ and $24 \%$ compared to SCC made with tap water at the ages of 28 and 90 days, respectively. Meanwhile, the simultaneous utilization of magnetic water and $20 \% \mathrm{NZ}$ led to a decrease in water absorption of SCC up to $48 \%$. Regarding this aspect, it can be concluded that higher content of NZ causes to reduce water absorption more. Furthermore, it was pointed out that NZ in SCC mixed with magnetic water can decrease the water absorption of SCC as curing age increases. 
- As a result, it seems that SCC prepared with magnetic water and containing $20 \%$ of $\mathrm{NZ}$ with the W/B ratio of 0.37 can be considered as an optimum mix design where engineering properties requirements were satisfied better than other concrete mixes. This matter showed that simultaneous utilization of NZ and magnetic water in SCC can efficiently reduce the hazardous burden on the environment by decreasing the amount of cement in SCC up to $20 \%$.

\section{Conflict of Interest}

The authors declare that there is no conflict of interest concerning this article.

\section{References}

ACI Committee 318-05. (2005). Building code requirements for structural concrete. American Concrete Institute, USA.

Afshin, H., Gholizadeh, M. \& Khorshidi, N. (2010). Improving mechanical properties of high strength concrete by magnetic water technology. Journal Scientia Iranica. Transaction A, 17(1), 74-79.

Ahmadi, B. \& Shekarchi, M. (2010). Use of natural zeolite as a supplementary cementitious material. Cement and Concrete Composites, 32(2), 134-141.

ASTM C469. (2002). Standard test method for static modulus of elasticity and poisson's ratio of concrete in compression. ASTM International, West Conshohocken, PA, USA.

ASTM C642. (2006). Standard test method for density, absorption, and voids in hardened concrete, ASTM International, West Conshohocken, PA, USA. 
ASTM C494. (2004). Standard Specification for Chemical Admixtures for Concrete. ASTM International, West Conshohocken, PA, USA.

ASTM C496. (2004). Standard test method for splitting tensile strength of cylindrical concrete specimens, ASTM International, West Conshohocken, PA, USA.

Babu, T.S., Rao M.V.S. \& Seshu R.D. (2008). Mechanical properties and stress- strain behavior of selfcompacting concrete with and without glass fibres. Asian Journal of Civil Engineering, 9(5), 457-472.

Beygi, M.H.A., Kazemi, M.T., Nikbin, I.M. \& Vaseghi, A.J. (2013). The effect of water to cement ratio on fracture parameters and brittleness of self-compacting concrete. Materials \& Design, 50, 267-276.

Billberg P. (1999). Self-compacting concrete for civil engineering structures - The Swedish experience. CBI report 2:99.

Bhatath, S., Subraja, S. \& Kumar P.A. (2016). Influence of magnetized water on concrete by replacing cement partially with copper slag. Journal of Chemical and Pharmaceutical Sciences, 9(4).

Canpolat, F., Yılmaz, K., Kose, M.M., Sumer, M. \& Yurdusev, M.A. (2004). Use of zeolite, coal bottom ash and fly ash as replacement materials in cement production. Cement and Concrete Research, 34(5), 731-735.

CEB-FIP. (1989 ). Diagnosis and assessment of concrete structures-state of the art report. CEB Bull, 192, 83-5.

Chan, S.Y.N. \& Ji, X. (1999). Comparative study of the initial surface absorption and chloride diffusion of high performance zeolite, silica fume and PFA concretes. Cement and Concrete Composites, 21(4), 293-300.

Chau, Z.J. (1996). The new construction method of concrete. The Publishing House of Chinese Architectural Industry, 401-407.

Cioffi, R., Colangelo, F., Caputo, D. \& Ligiori, B. (2006). Influence of high volumes of ultra-fine additions on self-compacting concrete, In: Malhotra, V.M., editor. Proceedings of the 8th Canmet/ACI international conference on fly ash, silica fume, slag, and natural pozzolans in concrete, Sorrento: Farmington Hills; 118135. 
Dehwah, H.A.F. (2012). Mechanical properties of self-compacting concrete incorporating quarry dust powder, silica fume or fly ash. Construction and Building Materials, 26(1), 547-51.

Domone, P.L. (2007). A review of the hardened mechanical properties of self-compacting concrete. Cement and Concrete Composites, 29(1), 1-12.

EFNARC (2005). The European guidelines for self-compacting concrete, The European federation of specialist construction chemicals and concrete systems, Specification production and use, 1-66. <www.efnarc.org>.

Esfahani, A.R., Reisi, M. \& Mohr, B. (2018). Magnetized water effect on compressive strength and dosage of superplasticizers and water in self-compacting concrete. Journal of Materials in Civil Engineering, 30(3), 04018008.

Feng, N.Q., Li, G.Z. \& Zang, X.W. (1990). High-strength and flowing concrete with a zeolite mineral admixture. Cement, Concrete and Aggregates, 12(2), 61-69.

Feng, N. \& Hao, T. (1998). Mechanism of natural zeolite powder in preventing alkali-silica reaction in concrete. Advances in Cement Research, 10(3), 101-108.

Fu, W. \& Wang, Z.B. (1994). The new technology of concrete engineering. The Publishing House of Chinese Architectural Industry, 56-59.

Gesoglu, M., Guneyisi, E., Mahmood, S.F., Oz, H.O. \& Mermerdas., K. (2012). Recycling ground granulated blast furnace slag as cold bonded artificial aggregate partially used in self-compacting concrete. Journal of Hazardous Materials, 352-358.

Ghods, A. (2014). A survey on the mechanical properties of magnetic self-compacting concrete containing nanosilica. International Research Journal of Applied and Basic Sciences, 8(4), 413-418.

Gholhaki, M., Kheyroddin, A., Hajforoush, M. \& Kazemi, M. (2018). An investigation on the fresh and hardened properties of self-compacting concrete incorporating magnetic water with various pozzolanic materials, Construction and Building Materials, 158, 173-80. 
Güneyisi, E., Gesoğlu, M. \& Mermerdaş, K. (2008). Improving strength, drying shrinkage, and pore structure of concrete using metakaolin. Materials and Structures, 41(5), 937-949.

Jahandari, S., Toufigh, M.M., Li, J. \& Saberian, M. (2018). Laboratory Study of the Effect of Degrees of Saturation on Lime Concrete Resistance Due to the Groundwater Level Increment. Geotechnical and Geological Engineering, 36(1), 413-424.

Jain, A., Laad, A., Singh, K. \& Murari, K. (2017). Effect of magnetic water on properties of concrete. International Journal of Engineering Science and Computing, 5(7).

Jalal, M., Mansouri, E., Sharifipour, M. \& Pouladkhan, A.R. (2012). Mechanical, rheological, durability and microstructural properties of high performance self-compacting concrete containing $\mathrm{SiO} 2$ micro and nanoparticles. Materials \& Design, 34, 389-400.

Khayat, K.H., Bickley, J. \& Lessard, M. (2000). Performance of self-consolidating concrete for casting basement and foundation walls, ACI Materials Journal, 97, 374-380.

Madandoust, R., Kazemi, M. \& Moghadam, S.Y. (2017). Analytical study on tensile strength of concrete, Romanian Journal of Materials, 47 (2), 204 - 209.

Madandoust, R., Ranjbar, M.M. \& Mousavi, S.Y. (2011). An investigation on the fresh properties of selfcompacted lightweight concrete containing expanded polystyrene. Construction and Building Materials, 25(9), 3721-3731.

Madandoust, R. \& Mousavi, S.Y. (2012). Fresh and hardened properties of self-compacting concrete containing metakaolin. Construction and Building Materials, 35,752-760.

Markiv T., Sobol, Kh., Franus, M., \& Franus, W. (2016). Mechanical and durability properties of concretes incorporating natural zeolite, Archives of Civil and Mechanical Engineering, 16(4), 554-562.

Mola-Abasi, H., Saberian, M., Semsani, S.N., Li, J. \& Khajeh, A. (2018). Triaxial behaviour of zeolitecemented sand, Proceedings of the Institution of Civil Engineers - Ground Improvement, https://www.icevirtuallibrary.com/doi/10.1680/jgrim.18.00009. 
Najimi, M., Sobhani, J., Ahmadi, B. \& Shekarchi, M. (2012). An experimental study on durability properties of concrete containing zeolite as a highly reactive natural pozzolan, Construction and Building Materials, 35, 1023-1033.

Nikbin, I.M., Beygi, M.H.A., Kazemi, M.T., Amiri, J.V., Rahmani, E., Rabbanifar, S. \& Eslami, M. (2014). A comprehensive investigation into the effect of aging and coarse aggregate size and volume on mechanical properties of self-compacting concrete. Materials \& Design, 59, 199-210.

Okamura, H. \& Ouchi, M. (2003). Self-Compacting Concrete. Journal of Advanced Concrete Technology, 1(1), 5-15.

Oner, A. \& Akyuz, S. (2007). An experimental study on optimum usage of GGBS for the compressive strength of concrete, Cement and Concrete Composites, 29(6), 505-514.

Otero, L., Rodríguez, A.C., Pérez-Mateos, M., \& Sanz,P.D. (2016) Effects of magnetic fields on freezing: application to biological products. Comprehensive Reviews in Food Science and Food Safety banner, 15(3), 646-667.

Pelisser, F., Vieira, A. \& Bernardin, A.M. (2018). Efficient self-compacting concrete with low cement consumption. Journal of Cleaner Production, 175, 324-332.

Poon, C.S., Lam, L., Kou, S.C. \& Lin, Z.S. (1999). A study on the hydration rate of natural zeolite blended cement pastes. Construction and Building Materials, 13(8), 427-432.

Ramezanianpour, A.A., Mousavi, R., Kalhori, M., Sobhani, J., \& Najimi, M. (2015). Micro and micro level properties of natural zeolite contained concretes. Construction and Building Materials, 101, 347-358.

Ranjbar, M.M., Madandoust, R., Mousavi, S.Y. \& Yosefi, S. (2013). Effects of natural zeolite on the fresh and hardened properties of self-compacted concrete. Construction and Building Materials, 47, 806-813.

Saberian, M., Jahandari, S., Li, J. \& Zivari, F. (2017). Effect of curing, capillary action, and groundwater level increment on geotechnical properties of lime concrete: Experimental and prediction studies. Journal of Rock Mechanics and Geotechnical Engineering, 9(4), 638-647. 
Safiuddin, M. (2008). Development of self-consolidating high performance concrete incorporating rice husk ash. PhD thesis, University of Waterloo, Canada.

Siddique, R. (2011). Properties of self-compacting concrete containing class F fly ash. Materials \& Design, 32(3), 1501-1507.

Singh, S. \& Naval, S. (2016). Effect of magnetic water on the engineering properties of self-compacting concrete using binary and ternary blends. International Journal of Science, Technology and Management, 9(1).

Su, N. \& Wu, C.-F. (2003). Effect of magnetic field treated water on mortar and concrete containing fly ash. Cement and Concrete Composites, 25(7), 681-688.

Su, N., Wu, Y-.H. \& Mar, C.Y. (2000). Effect of magnetic water on the engineering properties of concrete containing granulated blast furnace slag. Cement and Concrete Research, 30(4), $599-605$.

Topcu, I.B. \& Bilir, T. (2009). Experimental investigation of some fresh and hardened properties of rubberized self-compacting concrete. Materials \& Design, 30(8), 3056-3065.

Ubale, P., Pandit, R.D., \& Wadekar, A.P. (2016). Performance evaluation of magnetic field treated water on convectional concrete containing fly ash. International Journal of Science Technology and Management, $5(2), 68-77$.

Uysal, M. \& Tanyildizi, H. (2012). Estimation of compressive strength of self-compacting concrete containing polypropylene fiber and mineral additives exposed to high temperature using artificial neural network. Construction and Building Materials, 27(1), 404-14.

Valipour, M., Pargar, F., Shekarchi, M. \& Khani, S. (2013). Comparing a natural pozzolan, zeolite, to metakaolin and silica fume in terms of their effect on the durability characteristics of concrete: A laboratory study. Construction and Building Materials, 41, 879-88. 
Valipour, M., Yekkalar, M., Shekarchi, M. \& Panahi, S. (2014). Environmental assessment of green concrete containing natural zeolite on the global warming index in marine environments. Journal of Cleaner Production, 65, 418-423.

Yang, E.H., Yang, Y. \& Li, V.C. (2007). Use of high volumes of fly ash to improve ECC mechanical properties and material greenness. ACI Materials Journal, 104(6), 620-628. 


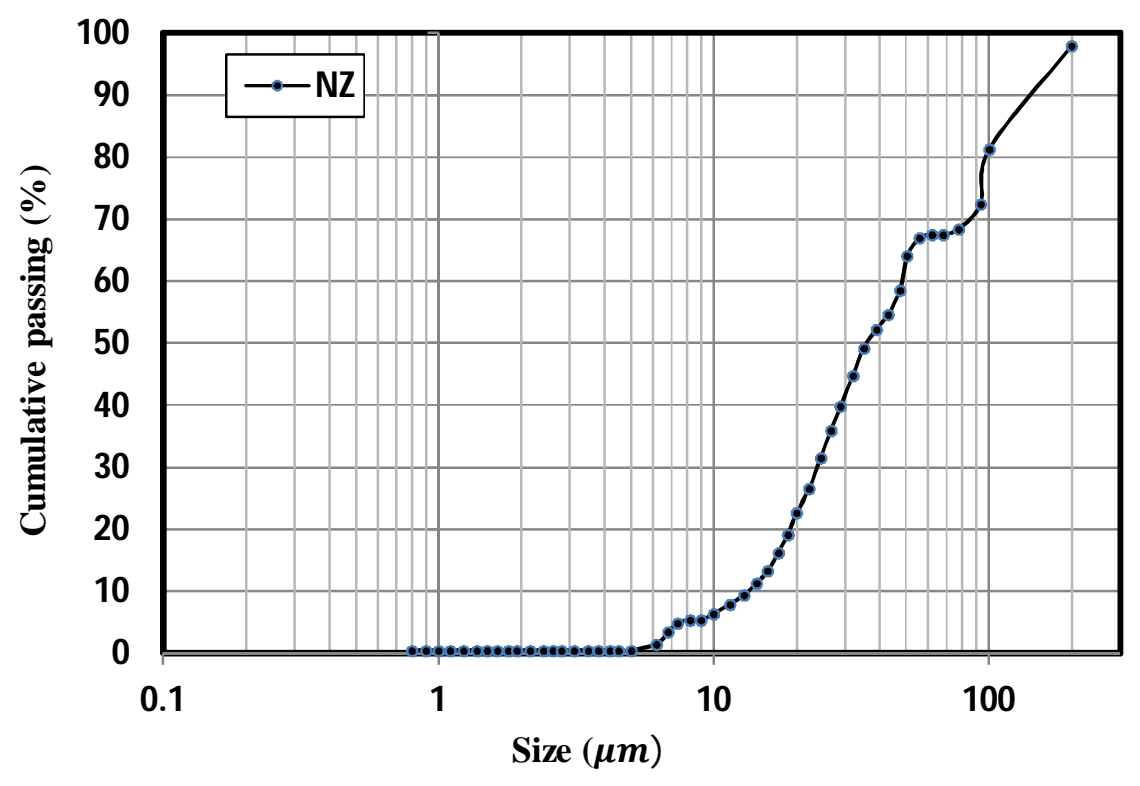

Fig. 1. Particle size distribution of NZ. 


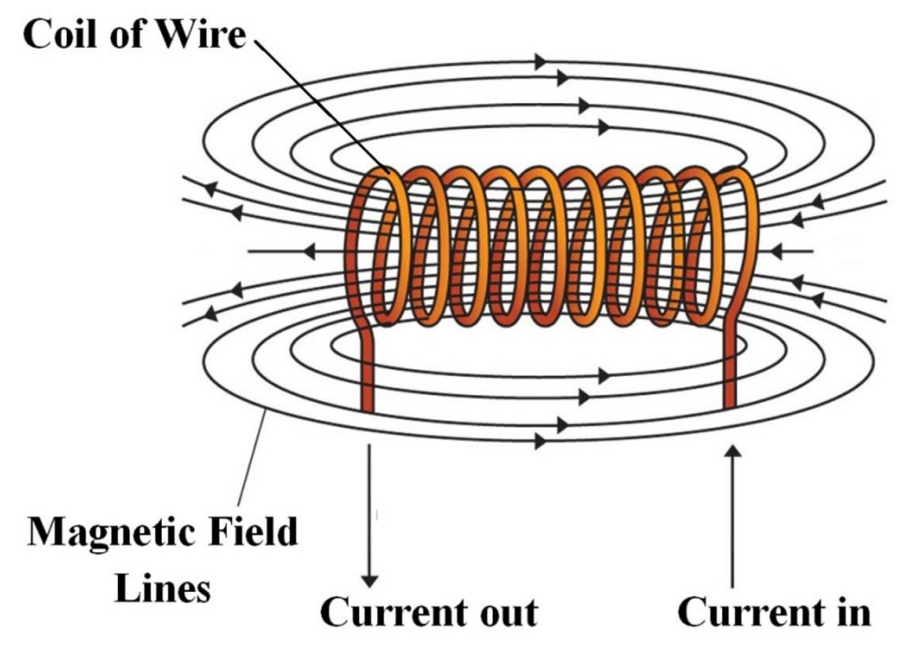

Fig. 2. Magnetic field pattern around the coil of wire. 


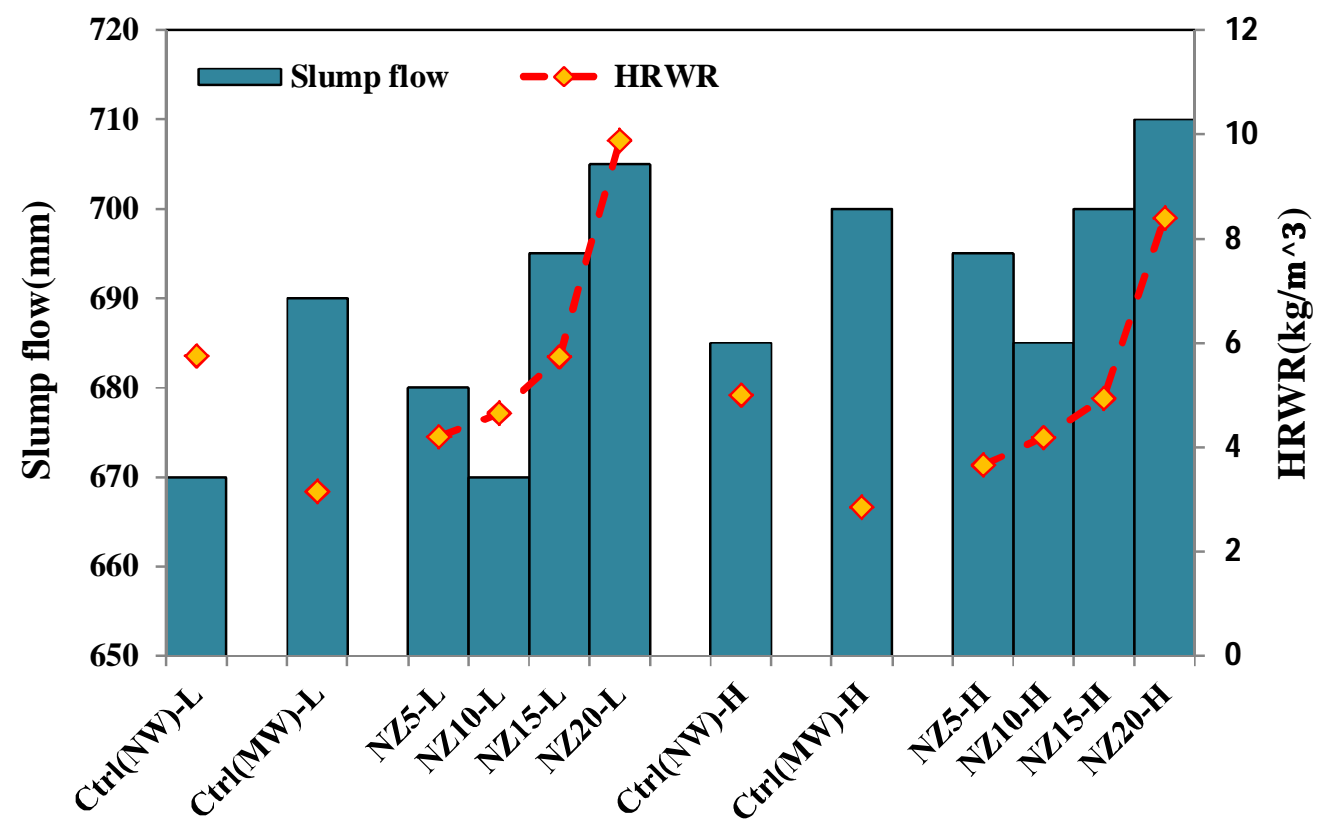

Fig. 3. The effect of magnetic water and NZ on HRWR content and the slump flow. 


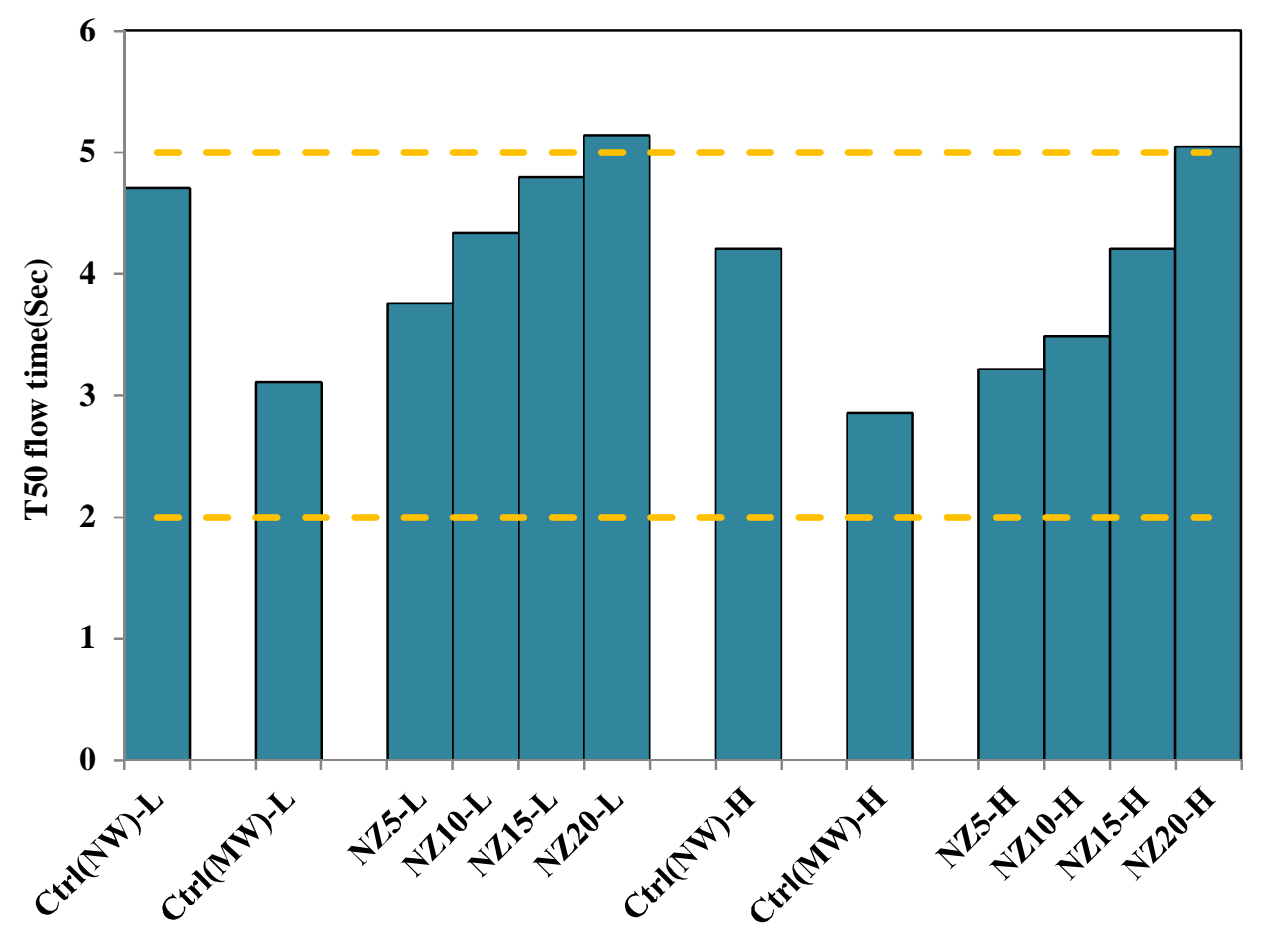

Fig. 4. The effect of magnetic water and $\mathrm{NZ}$ on the $\mathbf{T}_{\mathbf{5 0}}$ flow time. 


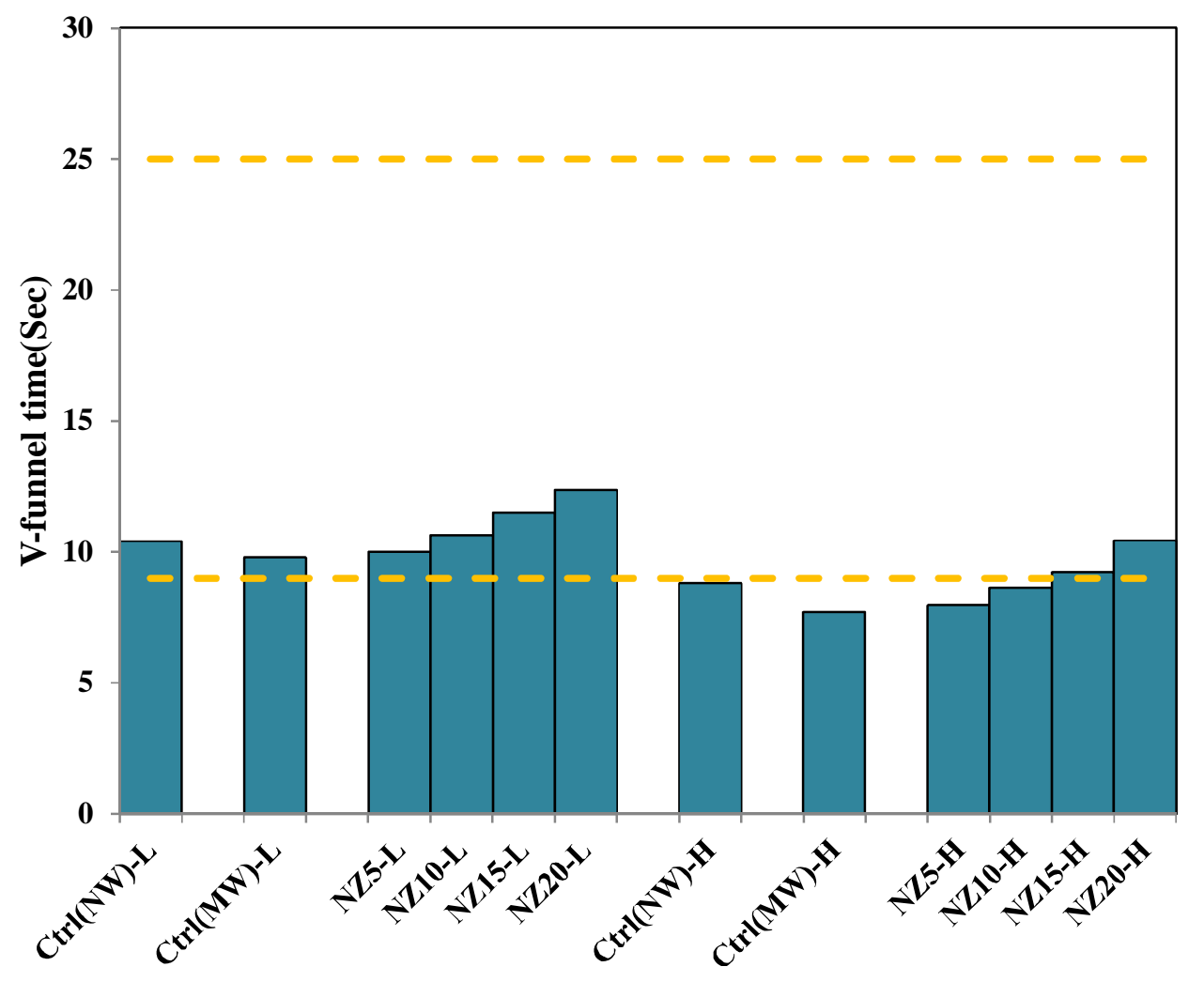

Fig. 5. The effect of magnetic water and NZ on the V-funnel time. 


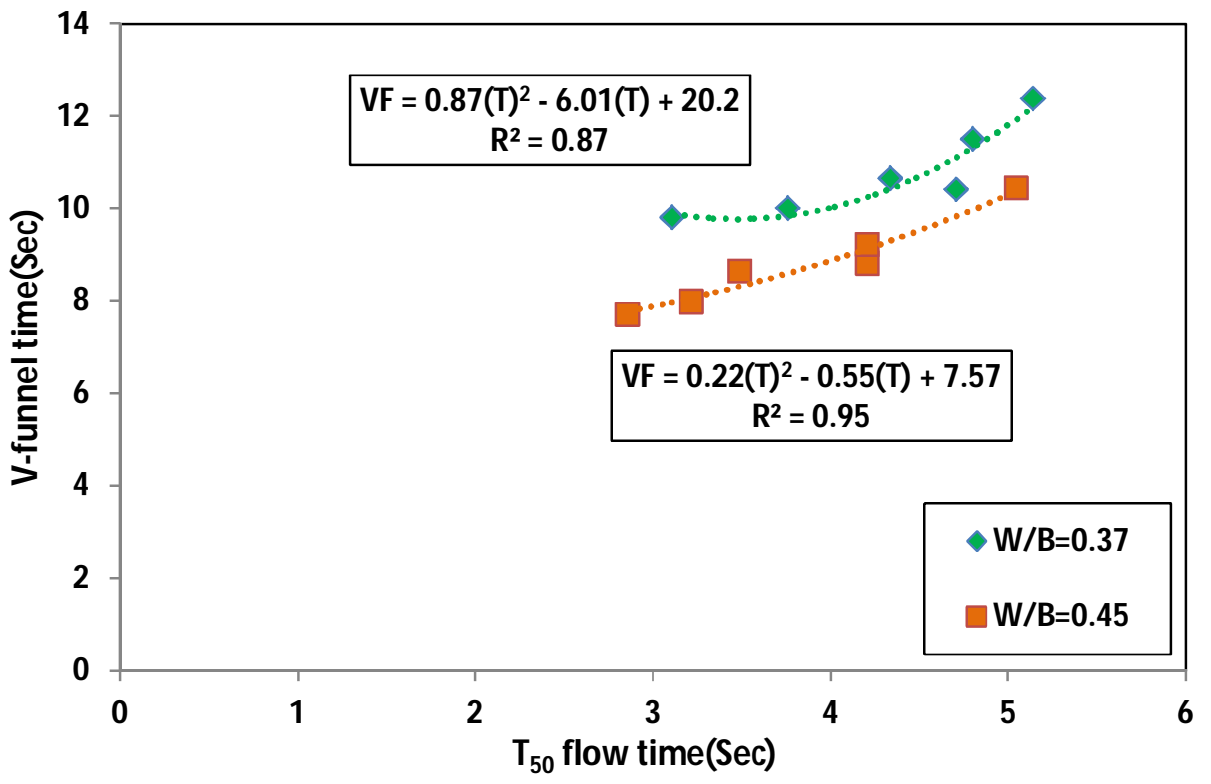

Fig. 6. Variation of viscosity classes with $\mathrm{T}_{50}$ and $\mathrm{V}$-funnel flow times. 


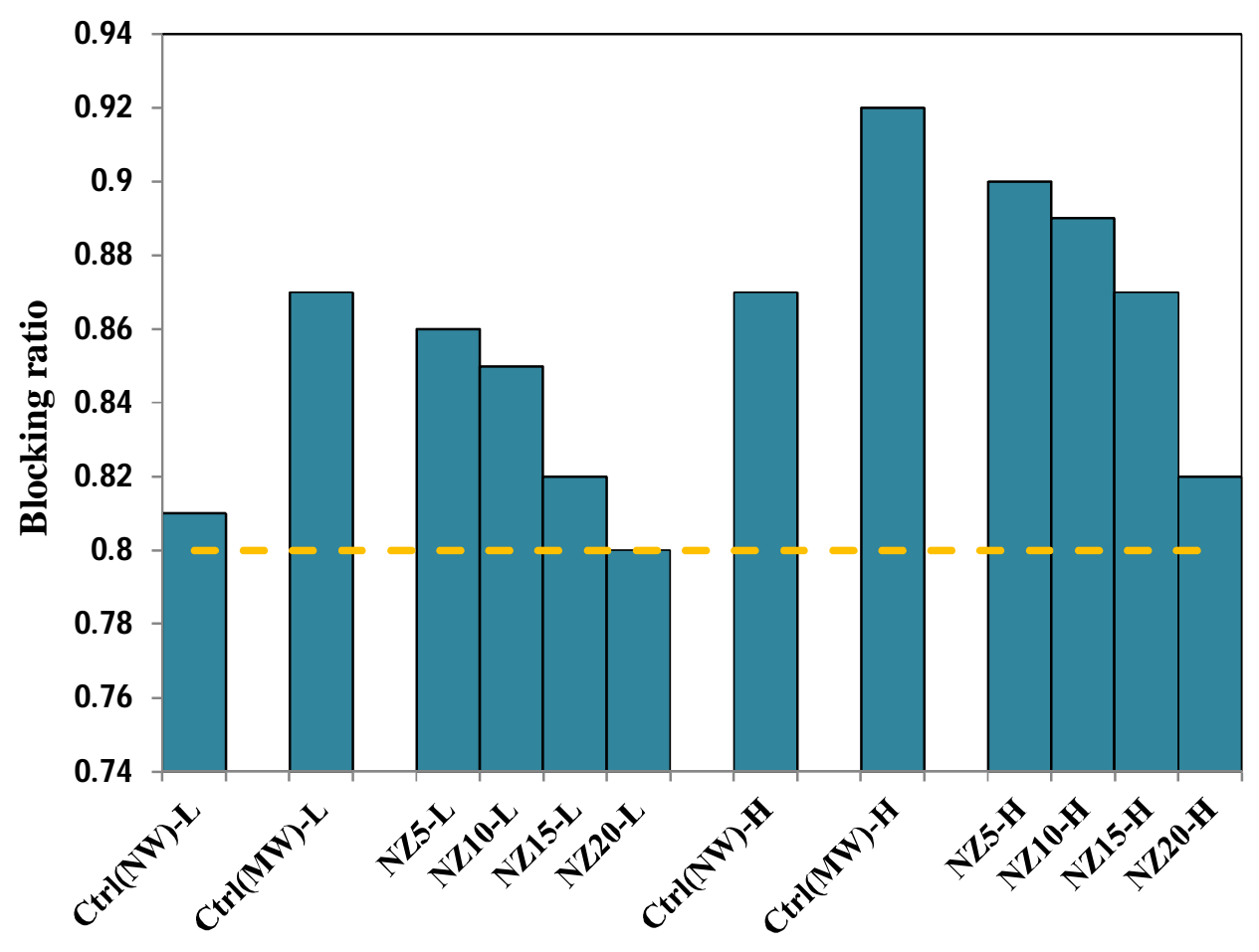

Fig. 7. Blocking ratio of SCC mixes. 

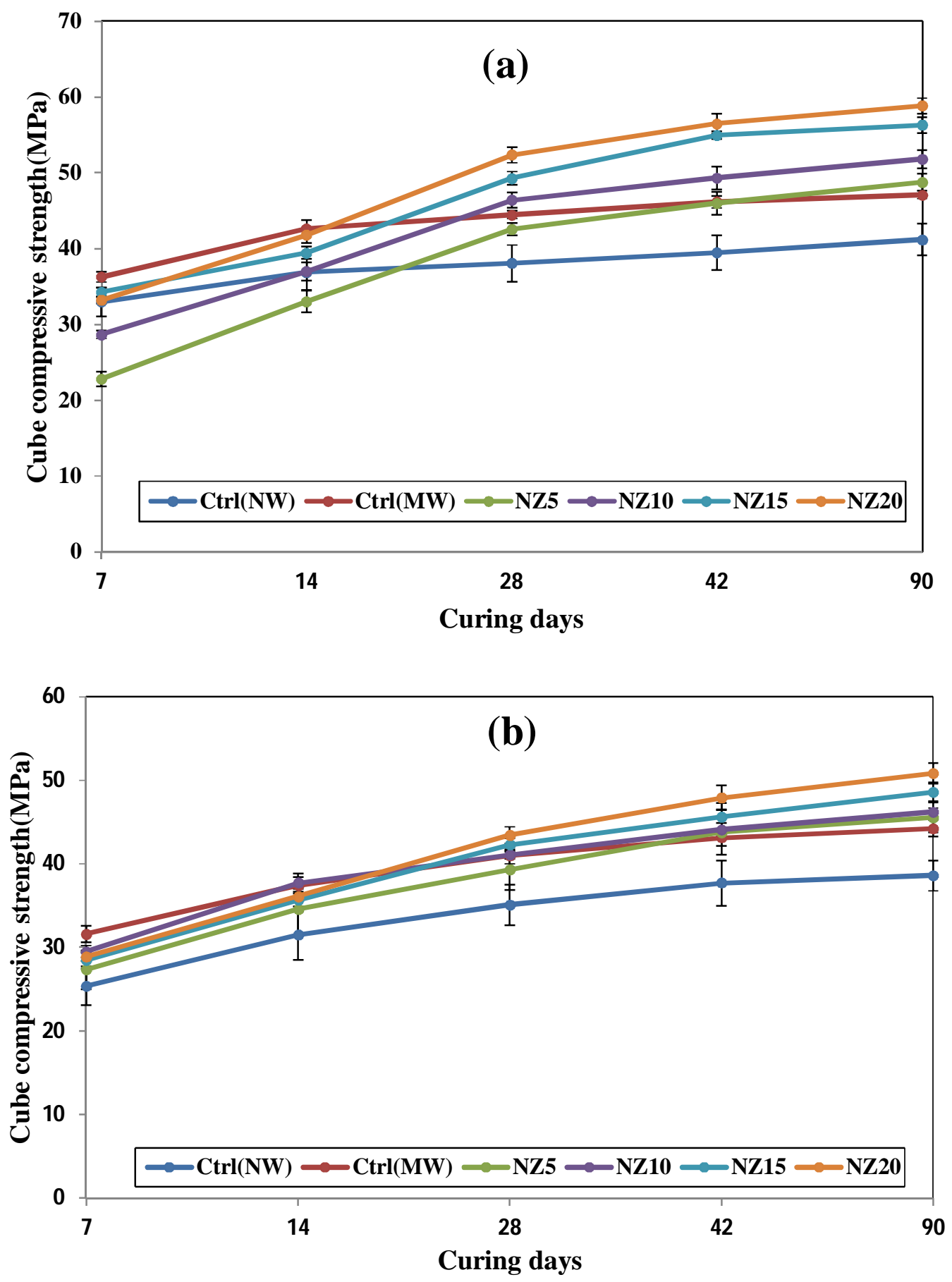

Fig. 8. Cube compressive strength of SCC mixes with W/B ratio of 0.37 (a) and 0.45 (b). 

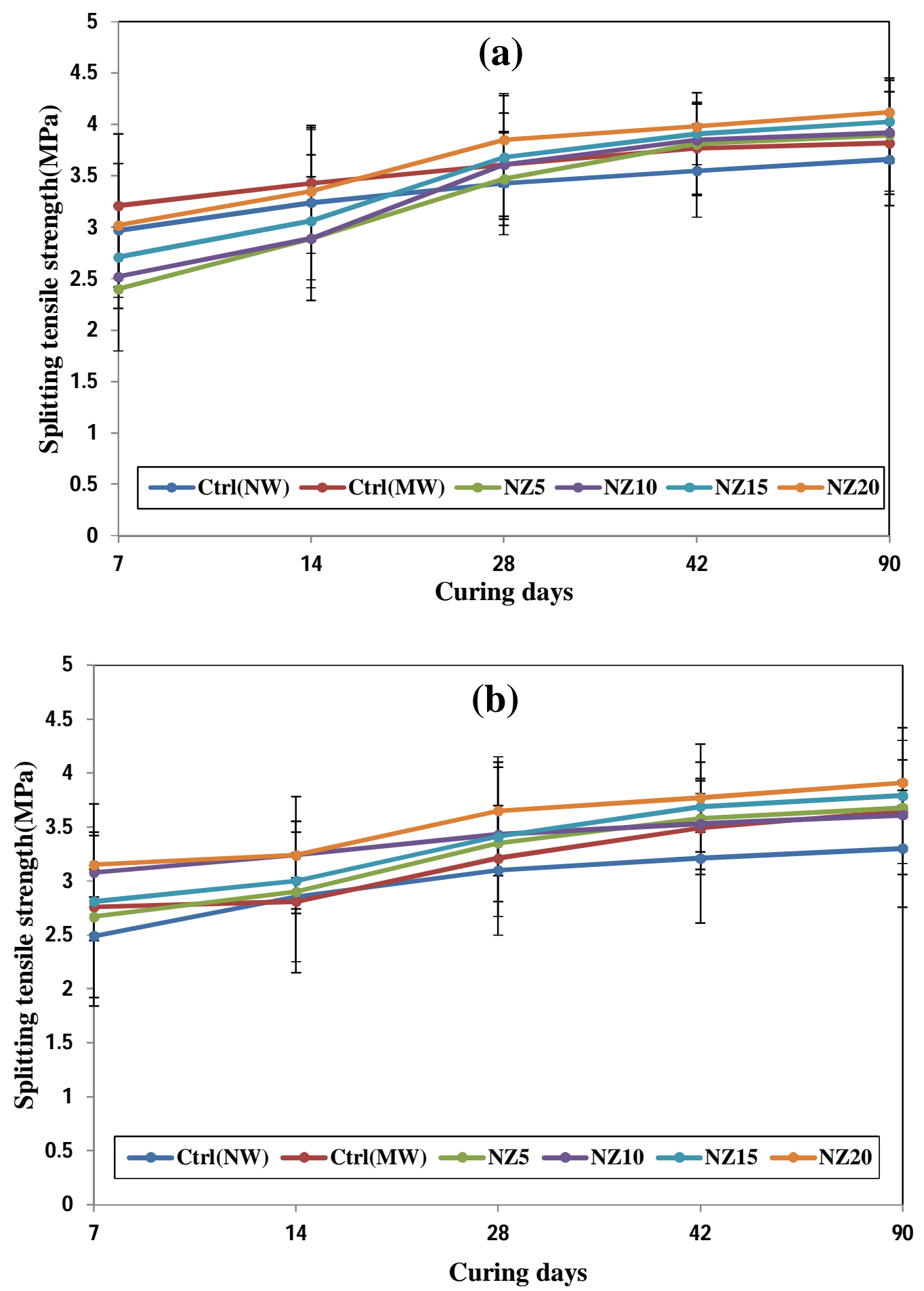

Fig. 9. Splitting tensile strength of SCC mixes with W/B ratio of 0.37 (a) and 0.45 (b). 


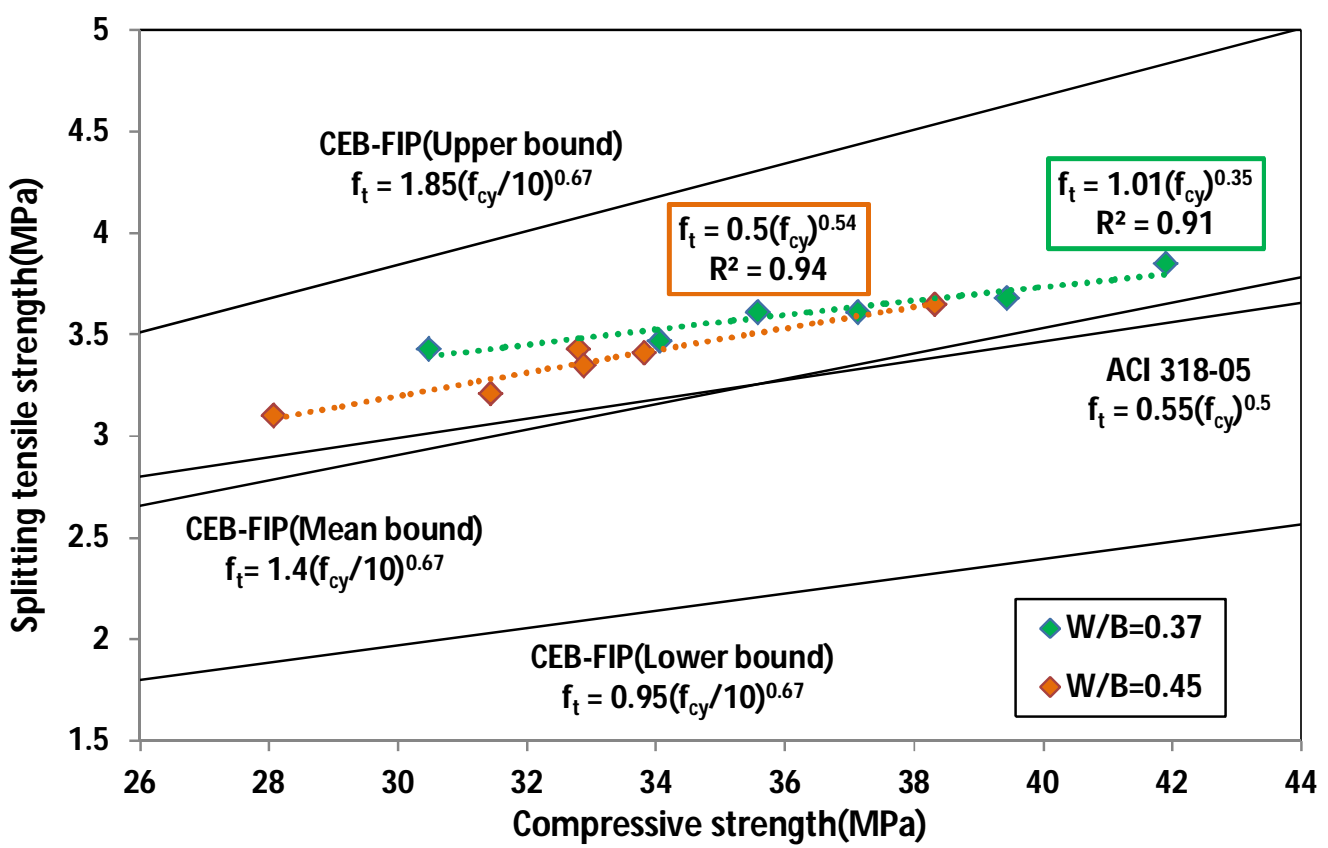

Fig. 10. Variation of splitting tensile strength vs. compressive strength at 28 days. 

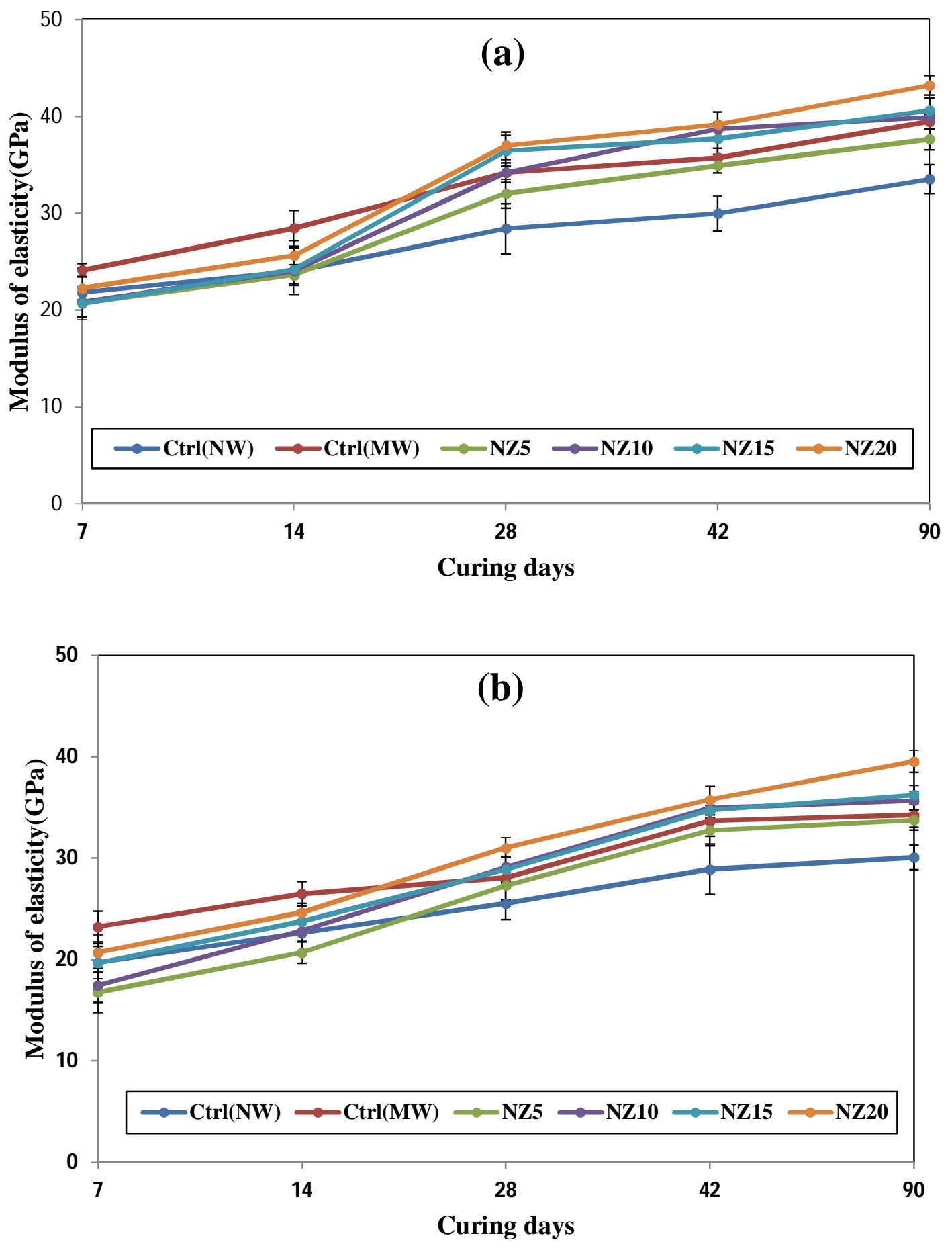

Fig. 11. Modulus of elasticity of SCC mixes with W/B ratio of 0.37 (a) and 0.45 (b). 


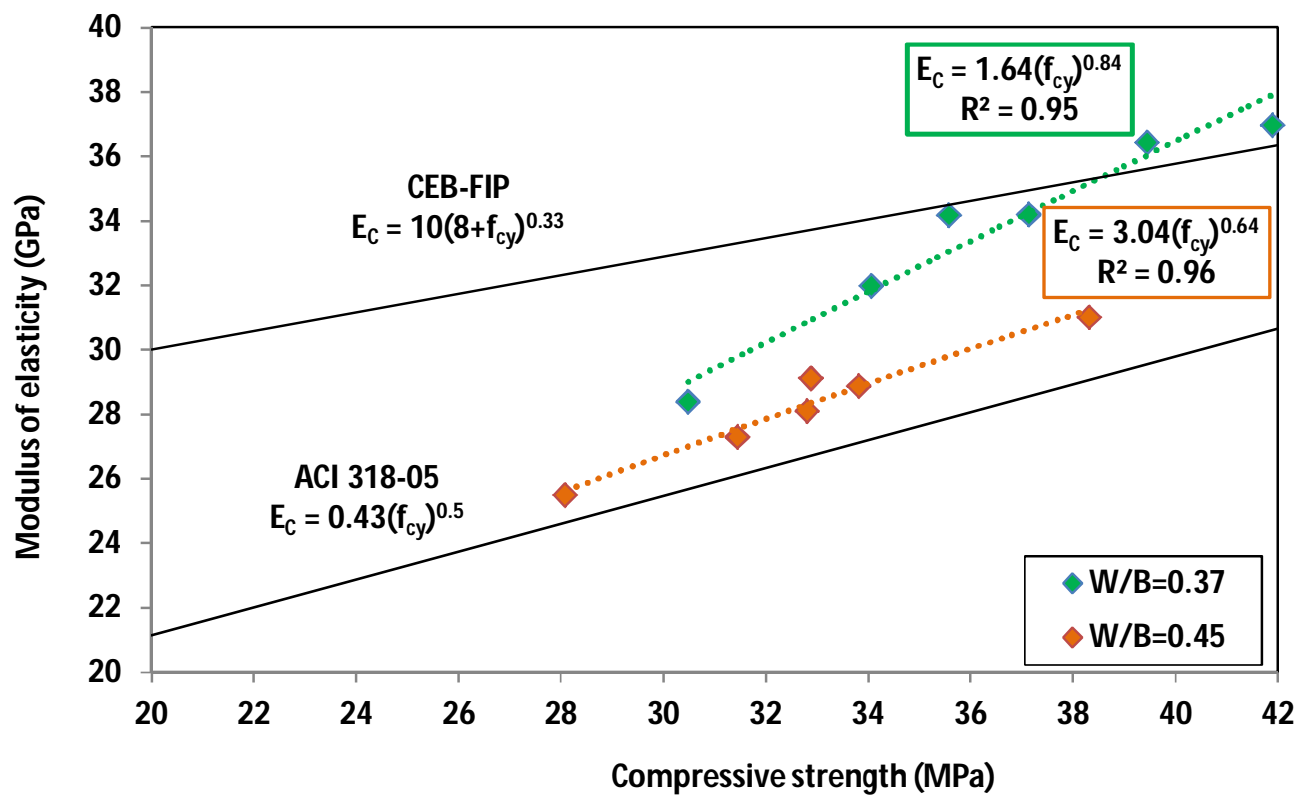

Fig. 12. Variation of modulus of elasticity vs. compressive strength at 28 days. 

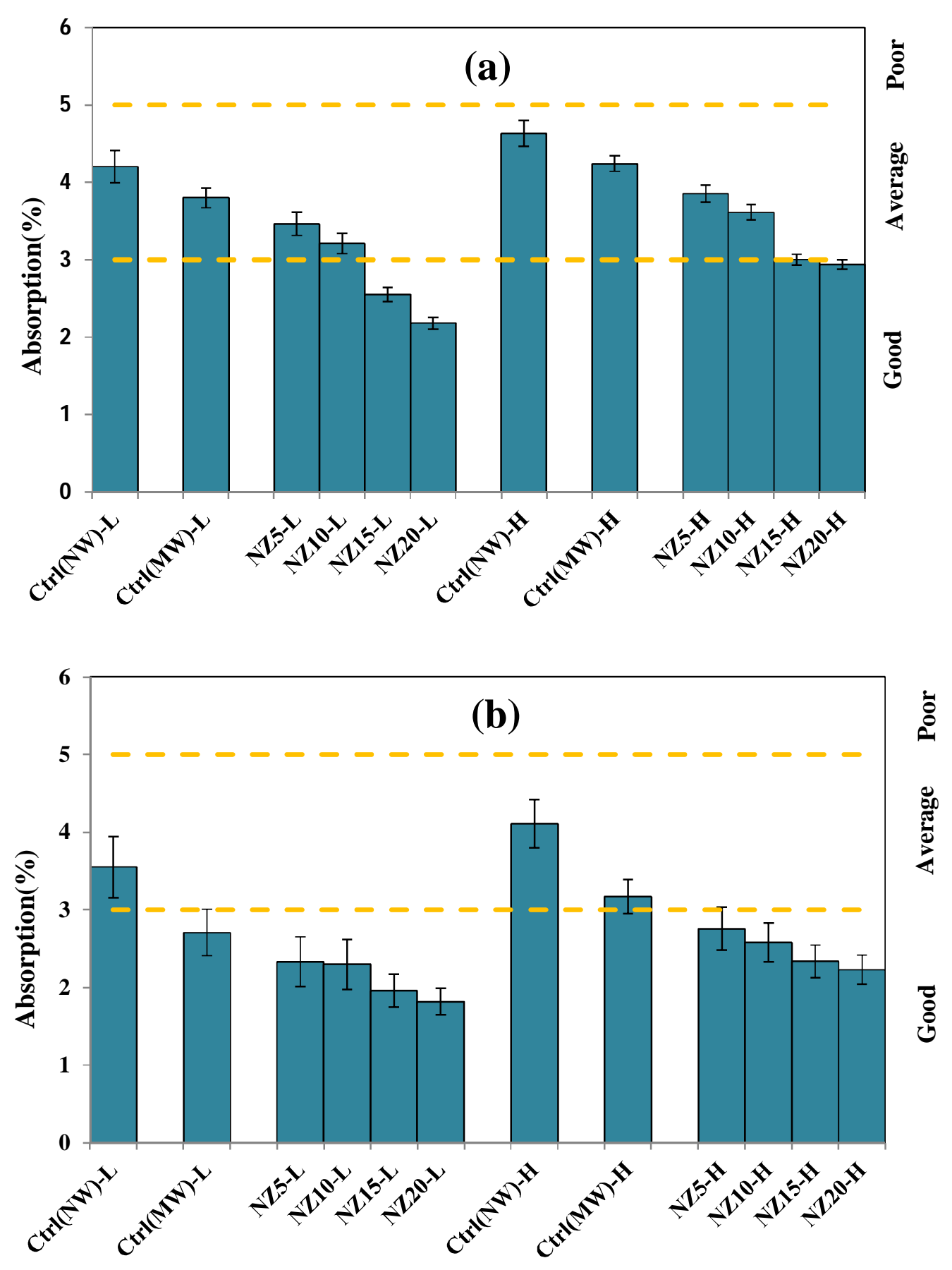

Fig. 13. Water absorption of SCC mixes at 28 days with W/B ratio of 0.37 (a) and 0.45 (b). 
Table 1. Chemical compositions of Portland cement and NZ.

\begin{tabular}{ccc}
\hline $\mathrm{XRF}$ & Cement (\%) & NZ (\%) \\
\hline $\mathrm{SiO}_{2}$ & 22.45 & 66.5 \\
$\mathrm{Al}_{2} \mathrm{O}_{3}$ & 4.85 & 11.81 \\
$\mathrm{Fe}_{2} \mathrm{O}_{3}$ & 3.95 & 1.3 \\
$\mathrm{CaO}$ & 64.86 & 3.11 \\
$\mathrm{MgO}$ & 0.8 & 0.72 \\
$\mathrm{SO}_{3}$ & 0.85 & - \\
$\mathrm{K}_{2} \mathrm{O}$ & 0.51 & 3.12 \\
$\mathrm{Na}_{2} \mathrm{O}$ & 0.25 & 2.01 \\
\hline
\end{tabular}


Table 2. Mix details.

\begin{tabular}{|c|c|c|c|c|c|c|c|c|c|}
\hline \multirow{2}{*}{$\begin{array}{l}\text { Mix. } \\
\text { NO. }\end{array}$} & \multirow[t]{2}{*}{ Mix. ID. } & \multirow{2}{*}{$\begin{array}{l}\text { Cement } \\
\left(\mathrm{kg} / \mathrm{m}^{3}\right)\end{array}$} & \multicolumn{2}{|c|}{$\mathrm{NZ}$} & \multirow{2}{*}{$\begin{array}{l}\text { Water } \\
\left(\mathrm{kg} / \mathrm{m}^{3}\right)\end{array}$} & \multirow{2}{*}{$\begin{array}{c}\text { Coarse } \\
\text { aggregate } \\
\left(\mathrm{kg} / \mathrm{m}^{3}\right)\end{array}$} & \multirow{2}{*}{$\begin{array}{c}\text { Fine } \\
\text { aggregate } \\
\left(\mathrm{kg} / \mathrm{m}^{3}\right)\end{array}$} & \multirow{2}{*}{$\begin{array}{l}\text { HRWR } \\
\left(\mathrm{kg} / \mathrm{m}^{3}\right)\end{array}$} & \multirow[t]{2}{*}{$\mathrm{W} / \mathrm{B}$} \\
\hline & & & (\%) & $\left(\mathrm{kg} / \mathrm{m}^{3}\right)$ & & & & & \\
\hline \multirow[t]{6}{*}{ G1 } & $\operatorname{Ctrl}\left(N W^{a}\right)-L^{b}$ & 400 & 0 & 0 & 148 & 778 & 1085 & 5.75 & 0.37 \\
\hline & $\operatorname{Ctrl}\left(M W^{c}\right)-\mathrm{L}$ & 400 & 0 & 0 & 148 & 778 & 1085 & 3.15 & 0.37 \\
\hline & NZ5-L & 380 & 5 & 20 & 148 & 778 & 1074 & 4.20 & 0.37 \\
\hline & NZ10-L & 380 & 10 & 40 & 148 & 778 & 1074 & 4.65 & 0.37 \\
\hline & NZ15-L & 340 & 15 & 60 & 148 & 780 & 1065 & 5.73 & 0.37 \\
\hline & NZ20-L & 320 & 20 & 80 & 148 & 780 & 1055 & 9.88 & 0.37 \\
\hline \multirow[t]{6}{*}{$\mathrm{G} 2$} & $\mathrm{Ctrl}(\mathrm{NW})-H^{d}$ & 400 & 0 & 0 & 180 & 778 & 1010 & 3.91 & 0.45 \\
\hline & $\mathrm{Ctrl}(\mathrm{MW})-\mathrm{H}$ & 400 & 0 & 0 & 180 & 778 & 1010 & 2.85 & 0.45 \\
\hline & NZ5-H & 380 & 5 & 20 & 180 & 778 & 1000 & 3.66 & 0.45 \\
\hline & NZ10-H & 360 & 10 & 40 & 180 & 770 & 1000 & 4.19 & 0.45 \\
\hline & NZ15-H & 340 & 15 & 60 & 180 & 750 & 1000 & 4.94 & 0.45 \\
\hline & NZ20-H & 320 & 20 & 80 & 180 & 750 & 1000 & 8.40 & 0.45 \\
\hline & $\begin{array}{l}\text { a Mixture made } \\
\text { b Low W/B ratio } \\
\text { c Mixture made } \\
\text { d High W/B ratio }\end{array}$ & ater & & & & & & & \\
\hline
\end{tabular}

